\title{
Long eccentricity cycles in oceanic carbon reservoir
}

\author{
Pinxian Wang and Jun Tian
}

\begin{abstract}
The 400-kyr eccentricity cycles dominate marine $\delta^{13} \mathrm{C}$ records until 1.6 Myr BP, coeval with the final formation of an abyssal carbon reservoir in the Southern Ocean. Eccentricity-driven global monsoon cycles are hypothetically responsible for this $400-k y r$ rhythm, which could have been further influenced by oceanographic processes related to polar ice-sheet growth.
\end{abstract}

\begin{abstract}
According to Milankovitch theory, Earth's eccentricity has periods of 100 and 400 thousand years (kyr). Therefore, a long eccentricity cycle (400 kyr) should be embedded in paleoclimate records. The absence of such a signal puzzled the paleoclimate community 30 years ago and was considered a fundamental problem in paleoclimate research ("the 400-kyr problem"). Recently, an increasing number of proxy records have revealed the existence of these 400-kyr cycles, at least in many records from the Cenozoic and Mesozoic (e.g. Giorgioni et al. 2012; Kocken et al. 2019). The remarkable 400-kyr eccentricity signal in deep-sea records now is referred to as the "heartbeat" of the ocean system (Pälike et al. 2006), and is used for astronomical calibration of the Cenozoic, Mesozoic, and beyond.
\end{abstract}

\section{Complexity of the $400-k y r ~ \delta^{13} \mathrm{C}$ signal}

Because of the long residence time of carbon in the oceanic reservoir greater than 100 $\mathrm{kyr}$, the long eccentricity cycle is best documented in the deep-sea $\delta^{13} \mathrm{C}$ records, with maximum values $\left(\delta^{13} C_{\max }\right)$ occurring at eccentricity minima. This $\delta^{13} \mathrm{C}$ oscillation reflects periodic changes in the sources and sinks of oceanic and atmospheric carbon, likely driven by the global monsoon. However, the mechanism remains unclear (Wang et al. 2017). The "rain-ratio hypothesis", for example, ascribed these $\delta^{13} \mathrm{C}$ cycles to the ratio of organic versus inorganic carbon deposition in the deep ocean, which is dominated by the ratio of diatoms to coccoliths (Archer et al. 2000). However, this was challenged by the discovery of the "ballast mineral" effect, as silicate and carbonate biominerals can affect deep-water flux of organic carbon (Armstrong et al. 2001). By contrast, the dissolved organic carbon (DOC) hypothesis (Wang et al. 2014) attributes the $\delta^{13} \mathrm{C}$ changes to the ratio between particulate and dissolved organic carbon (POC/DOC) in the ocean, which in turn depends on the monsoon-controlled nutrient supply. This DOC hypothesis was based on the recently identified microbial carbon pump (MCP) in the ocean (Jiao et al. 2010) and supported by numerical modeling (Ma et al. 2014).

The hypothesis discussed above does not account for the signal observed in $\delta^{13} \mathrm{C}$ records from the Quaternary. As displayed in Figure 1, the 400-kyr signal is clear in all $\delta^{13} \mathrm{C}$ timeseries from various oceans during the Pliocene, and a total of $13 \delta^{13} \mathrm{C}_{\max }$ events corresponding to long eccentricity minima have been identified (Wang et al. 2010). For the Quaternary, however, the rhythmic beat of $\delta^{13} \mathrm{C}_{\max }$ at long eccentricity minima ended at 1.6 million years before present (Myr BP), and the following $\delta^{13} C_{\max }$ events were out of phase with the minimum eccentricity signal; the records rather show a 500-kyr cycle over the last million years (Fig. 1). It remains unclear why the long eccentricity cycles disappeared in the Quaternary.

\section{Polar glaciation, Southern Ocean, and the 400-kyr cycles}

As shown by spectral analysis, the 400-kyr eccentricity signal in $\delta^{13} \mathrm{C}$ records became obscured after 1.6 Myr BP at all open-ocean sites but not in the Mediterranean Sea, which has been largely isolated from the global ocean since the late Miocene (Fig. 1e). Accordingly, the disappearance of the 400 kyr cyclicity around 1.6 Myr BP might be attributed to the restructuring of the global ocean, which disturbed responses of the oceanic carbon reservoir to the long eccentricity cycle. This in particular refers to formation of an abyssal carbon reservoir in the
Southern Ocean (SO), which began 1.6 Myr BP. Stratification of the polar water column started to drive vertical thermal stratification between deep and intermediate waters in the $\mathrm{SO}$ around $2.7 \mathrm{Myr} \mathrm{BP}$, isolating its abyss from the intermediate ocean and finally generating the largest carbon reservoir in the global ocean since 1.6 Myr BP (Hodell and Venz-Curtis 2006).

Since then, the ocean circulation has been divided into an actively circulating upper branch and a sluggish abyssal branch in the $\mathrm{SO}$. As the restructuring of the ocean was accompanied by the growth of polar ice sheets, it is plausible that global glaciation modulates responses of oceanic carbon cycles to the orbital forcing. This is supported by empirical evidence showing that the long eccentricity signal in the marine $\delta^{13} \mathrm{C}$ records starts to vanish at $1.6 \mathrm{Myr} \mathrm{BP}$ (Wang et al. 2014). It is possible that mechanisms of polar ice-sheet growth disturbing the long-term carbon cyclicity show parallels to some climate events in the Miocene. For

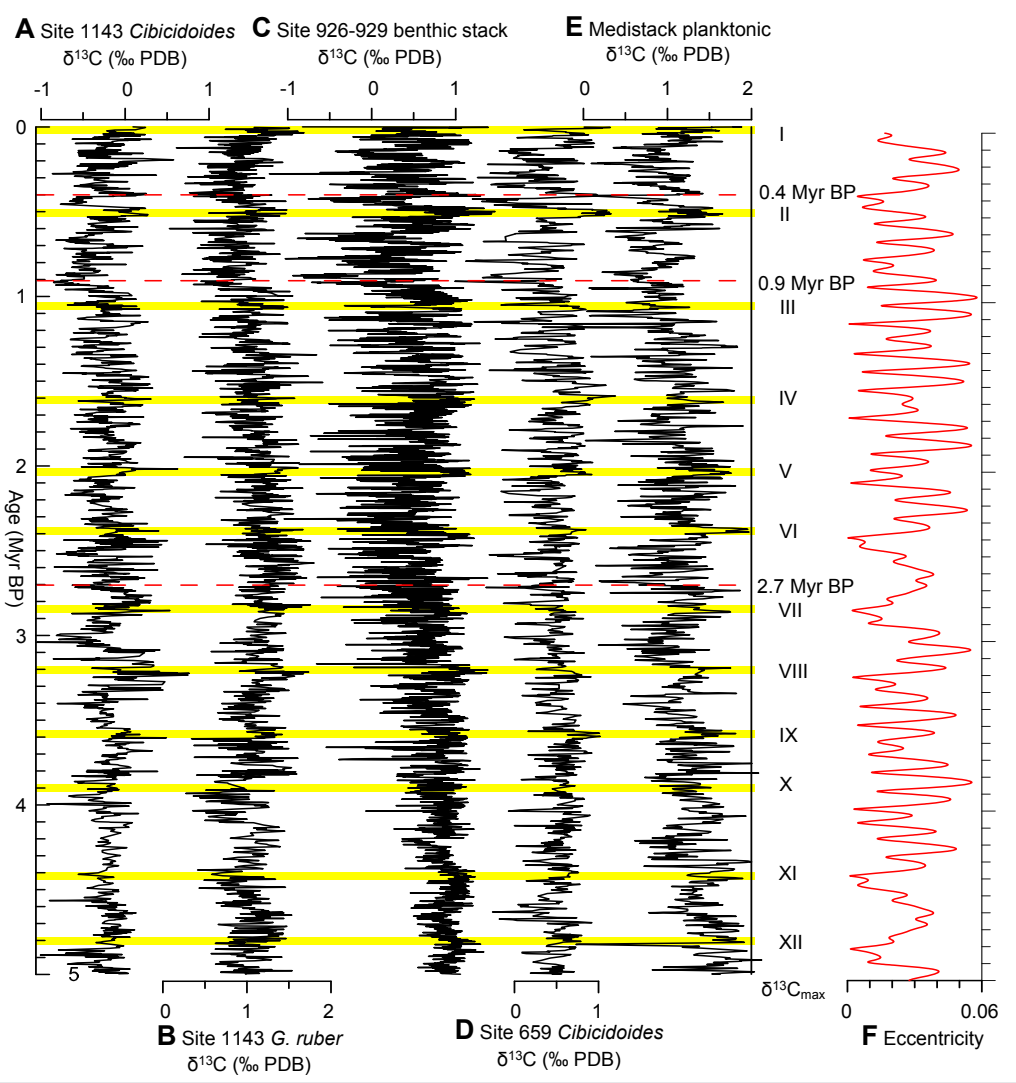

Figure 1: Carbon isotopic records from various oceans over the past $5 \operatorname{Myr}$ (A), (B) ODP Site 1143, South China Sea; (C), (D) Atlantic; (E) Mediterranean stack; (F) Eccentricity. Yellow bars indicate the $\delta^{13} C_{\max }$ events (modified from Wang et al. 2014). 


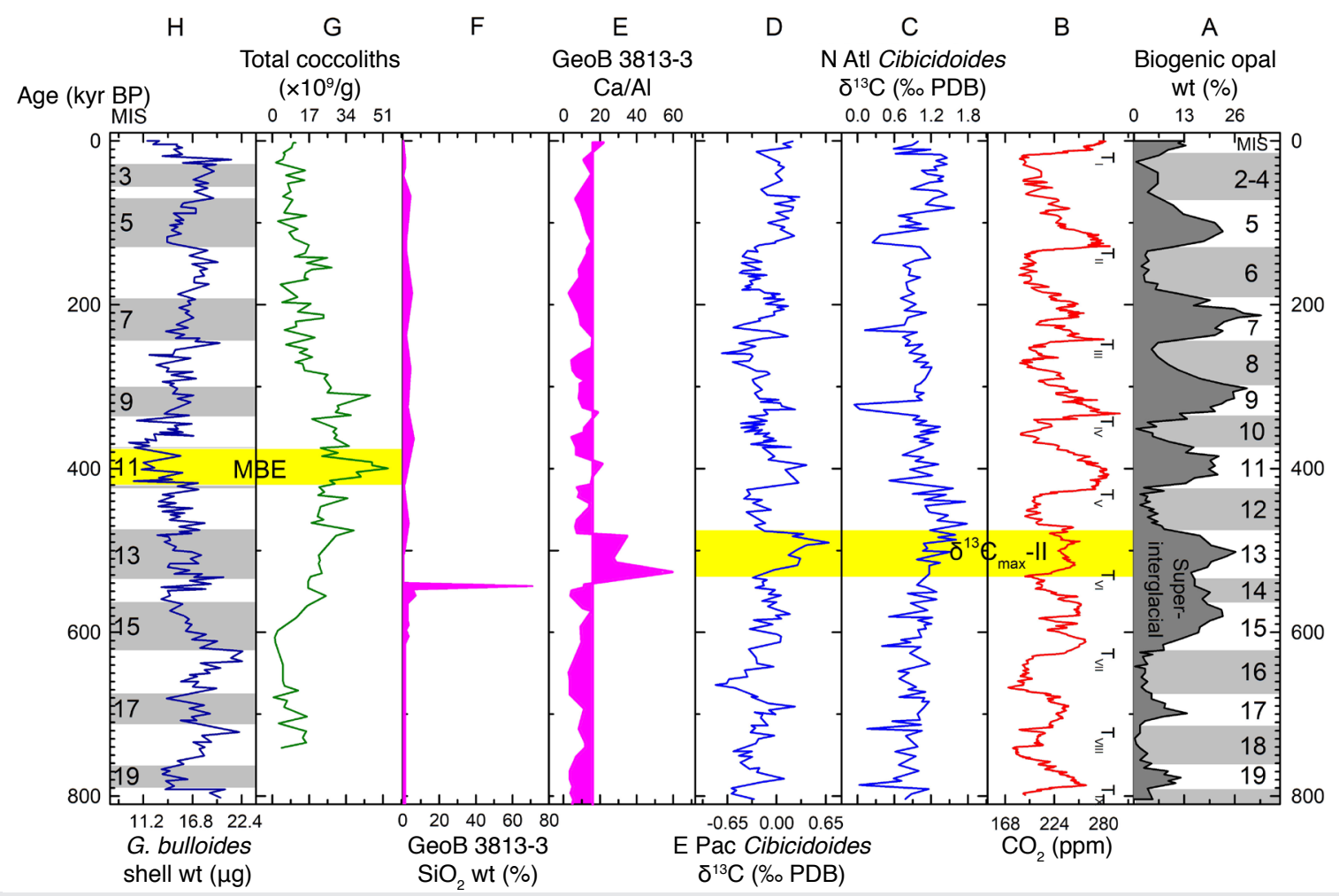

Figure 2: Connection between the $\delta^{13} \mathrm{Cmax}-I I$ and Mid-Brunhes events. (A) Biogenic opal wt \% in Core PS28-254, off W. Antarctic (Hillenbrand et al. 2009); (B) Ice-core CO, (ppm) at EPICA Dome C (Lüthi et al. 2008); (C), (D) Benthic $\delta^{13} \mathrm{C}$ at ODP 982 and ODP 849 (Barker et al. 2001); (E), (F) Ca/Al ratio and biogenic opal in Core GeoB 3813-3, S. Atlantic, respectively (Gengele and Schimitder 2001); (G) Total coccoliths from ODP 1082, SO; (H) Globigerina bulloides shell weight as dissolution index from ODP 982, N. Atlantic (Barker et al. 2006)

example, the eccentricity-forced $\delta^{13} \mathrm{C}$ signal was temporarily obscured around 13.9 Myr BP, presumably as a consequence of the amplification of the Antarctic ice sheet (Holbourn et al. 2007; Tian et al. 2014).

Clearly, the oceanic $\delta^{13} \mathrm{C}$ oscillation on a $10^{5}$-year timescale is controlled by both astronomical and oceanographic factors. Astronomically, the oceanic carbon reservoir responds to changes in the POC/DOC ratio, which result from changes in the monsoondriven nutrient supply. Oceanographically, the abyssal carbon reservoir in the SO might modulate the $\mathrm{DOC}$ distribution in the ocean by high-latitude processes associated with ice-sheet growth and decay. As a result, the oceanic $\delta^{13} \mathrm{C}$ signal is dominated by a regular 400-kyr beat when the low-latitude processes prevail, such as in the ice-free Hot-House world (Miller et al. 1991). In the Ice-House world, on the other hand, the 400 -kyr rhythm in the $\delta^{13} \mathrm{C}$ sequence can be obscured by processes associated with ice-sheet development. This may provide an explanation for the observed disappearance of $400-\mathrm{kyr} \delta^{13} \mathrm{C}$ cycles in the Quaternary after 1.6 Myr BP.

\section{0-kyr $\delta^{13} \mathrm{C}$ cycles and}

\section{Quaternary climate transitions}

Changes in the long-term cyclicity of the oceanic carbon reservoir may have serious climatic consequences. Two such changes occurred during the last million-year period, namely the mid-Pleistocene transition (MPT) centered at 0.9 Myr BP and the mid-Brunhes event (MBE) around 0.4 Myr BP. Importantly, both were preceded by $\delta^{13} \mathrm{C}$ events: the MPT by $\delta^{13} \mathrm{C}_{\max }-\mathrm{III}(\sim 1.0 \mathrm{Myr} \mathrm{BP})$, and the MBE by $\delta^{13} \mathrm{C}_{\text {max }}$-II ( 0.5 Myr BP) (Fig. 1; Wang et al. 2004). This indicates that changes in the oceanic carbon reservoir might be strong enough to cause such a major climatic shift during glacial periods. If so, the next step is to determine the potential driving mechanisms and the role of the Southern Ocean.

Figure 2 illustrates how $\delta^{13} \mathrm{C}_{\max }-11$ could have led to the MBE via processes in the SO. The event $\delta^{13} \mathrm{C}_{\max }$-II occurred during the younger part of the "super-interglacial" spanning from marine isotope stage (MIS) 15 to 13 (621-478 kyr BP; Fig. 2a-d), associated with a possible collapse of the West Antarctic Ice Sheet (Hillenbrand et al. 2009). The abnormally prolonged stratification in the SO during this period led to a large increase in the abyssal reservoir of Si and other nutrients. Meanwhile, the northward leakage of its Sirich water to the low-latitude ocean caused a series of biogeochemical events including basin-scale sub-surface diatom blooms in the Southern Atlantic and the accumulation of the vast laminated diatom mat deposits (Fig. 2f). This was followed by coccolithophore blooms when Si was exhausted (Fig. 2e; Gingele and Schmieder 2001). In parallel, the small-sized coccolithophore assemblages began to dominate the global ocean during MIS 15, peaking in MIS 11 and leading to the deep-water carbon dissolution that characterized the mid MBE (Fig. 2g-h; Barker et al. 2006). Therefore, $\delta^{13} C_{\max }-11$ was connected to the MBE by a sequence of events, and probably a similar connection also exists between the $\delta^{13} \mathrm{C}_{\max }-111$ and the MPT (Wang et al. 2014).

Since the Earth is currently in a new $\delta^{13} C_{\text {max }}$ it is crucial to understand the nature of $\delta^{13} C_{\max }$ events and their impacts on the global climate and ocean. This is particularly important for the debates on the next glacial inception (e.g. Berger and Loutre 2002; Müller and Pross 2007). We thus suggest that climate models with a carbon cycle should be used to test hypotheses regarding the dynamics of the carbon cycle in the past on long timescales, which will be crucial for us to improve our long-term future projections.

\section{AFFILIATION}

State Key Laboratory of Marine Geology, Tongji University, Shanghai, China

\section{CONTACT}

Pinxian Wang: pxwang@tongji.edu.cn

\section{REFERENCES}

Archer D et al. (2000) Rev Geophys 38: 159-189 Armstrong RA et al. (2001) Deep-Sea Res Pt II 49: 219-236 Barker S et al. (2006) Quat Sci Rev 25: 3278-3293

Berger A, Loutre MF (2002) Science 297: 1287-1288 Gingele FX, Schmieder F (2001) Earth Planet Sc Lett 186: 93-101

Giorgioni MH et al. (2012) Paleoceanography 27: PA1204 Hillenbrand C-D et al. (2007) Quat Sci Rev 28: 1147-1159 Hodell DA, Venz-Curtis KA (2006) Geochem Geophy Geosy 7: Q09001

Holbourn AE et al. (2007) Earth Planet Sc Lett 261: 534-550

Jiao N et al. (2010) Nat Rev Microbiol 8: 593-599 Kocken IJ et al. (2019) Clim Past 15: 91-104 Lüthi D et al. (2008) Nature 453: 379-382 Ma W et al. (2014) Geo-Marine Letters 34: 541-554 Miller K et al. (1991) J Geophys Res 69: 6829-6848 Müller UC, Pross J (2007) Quat Sci Rev 26: 3025-3029 Pälike H et al. (2006) Science 314: 1894-1898 Tian J et al. (2014) Earth Planet Sc Lett 406: 72-80 Wang P et al. (2004) Paleoceanography 19: A4005 Wang P et al. (2010) Earth Planet Sc Lett 290: 319-330 Wang P et al. (2014) Natl Sci Rev 1: 119-143 Wang P et al. (2017) Earth-Sci Rev 174: 84-121 